\title{
Substituição de farinhas de origem animal por ingredientes de origem vegetal em dietas para frangos de corte
}

\author{
Substitution of animal by-product meals by vegetable ingredients in diets for broilers
}

\author{
Claudio Bellaver ${ }^{1}$ Carlos Alberto Fagonde Costa ${ }^{2}$ Valdir Silveira de Avila ${ }^{3}$ Marcos Fraha $^{4}$ \\ Gustavo Júlio Mello Monteiro de Lima ${ }^{5}$ Leandro Hackenhar ${ }^{6}$ Paulo Baldi ${ }^{7}$
}

\section{RESUMO}

Devido às exigências de alguns importadores, por motivação cultural ou devido a zoonoses recém acontecidas na Europa, tem havido um direcionamento para fabricação de rações vegetais com base em milho e farelo de soja (FS). Esse direcionamento traz conseqüências na produção e por isso, objetivou-se avaliar a resposta de frangos de corte alimentados com dietas contendo farinhas de carne e ossos (FCO) e farinha de vísceras de aves (FV) e dietas contendo milho e FS. As dietas foram calculadas para conterem 3.050 e $3.150 \mathrm{kcal}^{\mathrm{EM} \mathrm{kg}} \mathrm{kg}^{-1}$ de ração nas fases inicial $e$ de crescimento, respectivamente, e com os demais nutrientes calculados para atenderem às exigências das aves. A substituição de ingredientes foi testada variando-se os níveis de proteina nas fases inicial e de crescimento respectivamente, da seguinte forma: 1. Dieta com inclusão de 4\% de FCO suína e 3\% de FV, calculada por proteína ideal, com $22 \%$ (inicial) e $20 \%$ de $P B$ (crescimento); 2. Dieta semelhante à dieta 1 , sem farinhas de origem animal, formulada a base de milho e FS, com $P B$ e lisina digestível semelhantes à dieta 1 ; 3. Dieta semelhante à dieta 2 , com $23 \%$ (inicial) e $21 \%$ de $P B$ (crescimento) e lisina digestível semelhante a dieta $1 ; 4$. Dieta semelhante à dieta 2 , com $24 \%$ (inicial) e $22 \%$ de PB (crescimento) e lisina digestível 6\% e 5\% superiores à dieta 1. Houve diminuição significativa da matéria seca da cama das aves devido à presença de ingredientes exclusivamente vegetais e aumento do teor de proteína das dietas $(P<0,0002)$, sendo que as fêmeas apresentam maior teor de matéria seca das camas do que os machos $(P<0,0003)$. O desempenho das aves alimentadas com proteína de origem vegetal foi superior ao de dietas contendo proteína animal; porém, em geral, é maior o custo de dietas exclusivamente vegetais. Nas dietas de origem vegetal, a dieta 4, com níveis superiores de aminoácidos, proporcionou melhor desempenho $(P<0,0002)$, não havendo resposta ao aumento apenas da PB. Não houve diferença nos cortes da carcaça devido às fontes protéicas $(P>0,05)$; havendo, porém, maior peso dos pés $(P<0,01)$ nas dietas com menor porcentagem de matéria seca da cama de aviário.

Palavras-chave: subprodutos de origem animal, proteína ideal, dietas vegetais, aminoácidos digestíveis, cama de aviário, carcaças.

\section{ABSTRACT}

The demand of some importers due to cultural reasons or to zoonosis that recently emerged in Europe, there has been a trend to manufacture vegetable feeds based on corn and soybean meal (SBM). This influences live production, and therefore, this study aimed at evaluating the response of broilers fed diets containing either meat and bone meal (MBM) and offal meal (OM), or vegetable diets based on corn and SBM. Diets were calculated to supply 3050 and 3150kcal ME $\mathrm{kg}^{-1}$ for the starter and grower phase, respectively, as well as to supply the requirements for all the other nutrients. The following treatments were tested: 1 . Diet with inclusion of $4 \%$ swine MBM and 3\% OM, calculated on Ideal Protein basis, containing $22 \%$ and $20 \%$ CP in the starter and grower phase,

\footnotetext{
${ }^{1}$ Médico Veterinário, PhD, Pesquisador da Embrapa Suínos e Aves, Bolsista do Conselho Nacional de Desenvolvimento Científico e Tecnológico (CNPq), CP 21, 89700-000, Concórdia, SC, Brasil. E-mail: bellaver@cnpsa.embrapa.br. ${ }^{2}$ Médico Veterinário, DSc, Pesquisador da Embrapa Suínos e Aves, Brasil. E-mail: ccosta@cnpsa.embrapa.br.

${ }^{3}$ Engenheiro Agrônomo, DSc, Pesquisador da Embrapa Suínos e Aves, Brasil, E-mail: vavila@cnpsa.embrapa.br. ${ }^{4}$ Médico Veterinário, MSc, Departamento Técnico da Purina Agribrands, São Paulo, SP, Brasil.

${ }^{5}$ Engenheiro Agrônomo, PhD, Pesquisador da Embrapa Suínos e Aves, Bolsista do CNPq, E-mail:gustavo@cnpsa.embrapa.br

${ }^{6}$ Engenheiro Agrônomo, MSc, Departamento Técnico da Ajinomoto Biolatina, São Paulo, SP, Brasil.

${ }^{7}$ Técnico Agrícola da Embrapa Suínos e Aves.
} 
respectively; 2. Diet similar to 1 , with no inclusion of animal meals, based on corn and SBM (similar CP and Digestible Lysine as to diet 1); 3. Diet similar to 2, but with $23 \%$ and 21\% CP (Digestible Lysine similar to diet 1); Diet similar to 2, but with 24\% and 22\% CP (Digestible Lysine 6\% and 5\% higher than in diet 1). Dry matter content of the litter of birds fed exclusively vegetable ingredients and higher protein levels significantly deceased $(P<0.0002)$, and it was higher in females as compared to males $(P<0.0003)$. The performance of birds fed vegetable diets was better than of those fed diets containing animal protein. However, the cost of exclusively vegetable diets is higher. Diet 4 , a vegetable diet with higher amino acid levels, promoted the best performance $(P<0,0002)$, but there was no response to the increase of only CP. There was no difference in carcass cuts due to protein sources $(P>0.05)$, but the feet weight was higher $(P<0.01)$ in birds with lower dry matter content in the litter.

Key words: animal by-products, ideal protein, vegetable diets, digestible amino acids, poultry litter, carcass.

\section{INTRODUÇÃO}

As agroindústrias processadoras de frangos no Brasil vêm aumentando a produção e o volume das exportações. Dados da Associação Brasileira dos Exportadores de Frangos (ABEF, 2001) mostram que o grande crescimento da produção de frangos tem sido direcionado às exportações para a Europa e Oriente Médio. Esse direcionamento implica o atendimento das exigências dos importadores o que tem reflexos imediatos nos sistemas produtivos aqui implantados.

A prática de alimentar os não ruminantes com dietas contendo farinhas de carne, vísceras e penas como fonte de proteína, substituindo o farelo de soja (FS), é bastante comum nas empresas brasileiras de integrações, sendo que essas matériasprimas apresentam custo relativamente baixo e são boas fontes de nutrientes quando bem processadas (MOURA et al., 1994; PEREIRA et al., 1994; BRUGALLI et al., 1999; BELLAVER et al., 2001b). No entanto, a ocorrência da Encefalopatia Espongiforme Bovina na Europa e o banimento das farinhas de origem animal para fabricação de rações animais naquele continente, levou os importadores a exigirem que os frangos brasileiros fossem alimentados com dietas formuladas com ingredientes estritamente vegetais, tais como o milho e o FS. Além disto, o mercado do Oriente Médio exige um frango produzido segundo normas religiosas específicas que também proíbem o uso de farinhas de origem animal nas rações dos frangos.

Uma observação de campo que carece de confirmação é a queda de desempenho de frangos arraçoados com dietas vegetais à base de milho e FS, mesmo quando são mantidos os mesmos níveis nutricionais. Também é observada empiricamente a piora da qualidade da cama, que se torna mais úmida, trazendo possíveis problemas de pata e peito. Do ponto de vista prático da formulação, as farinhas e gorduras de origem animal são substituídas por óleo, FS e fosfato bicálcico. Para um mesmo nível mínimo de $\mathrm{PB}$, a inclusão de aminoácidos industriais geralmente é diminuída nas dietas vegetais, o que torna a produção mais onerosa em relação às dietas com subprodutos de origem animal. Para tentar reverter o problema de desempenho, alguns nutricionistas têm elevado o nível mínimo de PB, com maior inclusão de FS, na expectativa que isto seja uma limitação da nutrição protéica. Esta prática gera um custo ainda maior destas formulações e contribui para agravar o problema de cama úmida em função da alta concentração de K+ no FS. Foi reportado por ROSTAGNO et al. (2002) que frangos alimentados com dietas vegetarianas a base de FS, com maior teor de $\mathrm{PB}$, levam ao maior consumo de água, o que pode levar a diferenças na umidade da cama. Devido à consistência de resultados, as dietas vegetarianas à base de milho e FS tem sido consideradas como dietas referência em pesquisas para avaliação de outros alimentos, inclusive para as farinhas de origem animal (PARSONS \& WANG, 1998 e BELLAVER et al., 2001b).

Assim, o objetivo deste trabalho foi avaliar a resposta de frangos de corte, machos e fêmeas, alimentados com dietas contendo farinhas de carne $\mathrm{e}$ ossos (FCO) e farinha de vísceras (FV) e dietas contendo milho e FS com vários níveis de proteína.

\section{MATERIAL E MÉTODOS}

O experimento foi realizado na granja Suruvi da Embrapa, Concórdia (SC), entre os dias 15 de fevereiro e 28 de março de 2002. Nesse período, as médias e os desvios padrões das temperaturas mínimas e máximas internas no galpão experimental, tomadas as 8 e 16 horas, foram respectivamente, 21,3 $\pm 1,9$ e $30,2 \pm 2,1^{\circ} \mathrm{C}$. Foram utilizados 1.200 machos e fêmeas de frangos de corte da linhagem Agroceres Ross, selecionados de um total de 1.300 pintos de um dia. $\mathrm{O}$ galpão experimental em que foi conduzido o experimento dispunha de boxes com piso de cimento, medindo $1,58 \times 1,80 \mathrm{~m}$, o qual foi coberto com uma camada de $8 \mathrm{~cm}$ de altura de maravalha de primeiro uso. Foram usados 40 boxes e, em cada boxe, foram colocadas 30 aves. O alimento e a água foram fornecidos à vontade. $\mathrm{O}$ programa de luz foi de $18 \mathrm{~h}$ de luz e 6 h de escuro com suprimento de calor artificial nos primeiros 14 dias de vida através de aquecedores a gás. 
As dietas foram adequadas em todos os nutrientes e energia, atendendo às exigências nutricionais conforme as especificações do NRC (1994), BAKER e HAN (1994) e PARSONS e BAKER (1994). As dietas foram baseadas em combinações dos ingredientes (Tabela 1) milho, farelo de soja (FS), farinha de carne e ossos (FCO), farinha de vísceras (FV), óleo de soja, minerais, vitaminas, suplementadas com aminoácidos e aditivos, fornecidas em programa de duas fases, conforme os tratamentos experimentais. A dieta inicial foi fornecida do primeiro dia até os 21 dias e a de crescimento de 22 dias até os 41 dias. As dietas foram calculadas para conterem no mínimo 3050kcal EM kg-1 , 1,00\% Ca e 0,45\% Pd na fase inicial e $3150 \mathrm{kcal} \mathrm{EM} \mathrm{kg}^{-1}, 0,90 \%$ Ca e $0,35 \%$ Pd na fase de crescimento, com os demais nutrientes calculados conforme mostrado nas tabelas 2 e 3 .

Os tratamentos testados foram: T1. Dieta com inclusão de 4\% de FCO suína e 3\% de FV de aves calculada por aminoácidos (AA) disponíveis equilibrados para proteína ideal e com a exigência de $1,16 \%$ e $1,05 \%$ de lisina digestível e $22 \%$ e $20 \%$ de PB nas fases inicial e de crescimento, respectivamente; T2. Dieta sem farinhas animais formulada à base de milho e FS com mesmos níveis nutricionais da dieta T1; T3. Dieta à base de milho e FS, formulada para AA digestíveis à semelhança da dieta $\mathrm{T} 1$, com $23 \%$ e $21 \%$ de $\mathrm{PB}$ nas fases inicial e de crescimento, respectivamente. O nível de lisina digestível foi mantido semelhante ao da dieta T1; T4. Dieta à base de milho e FS, formulada para AA digestíveis à semelhança da dieta T1, com $24 \%$ e $22 \%$ de $\mathrm{PB}$ nas fases iniciais e de crescimento, respectivamente. O nível de lisina digestível foi $6 \%$ e $5 \%$ superior em relação a dieta $\mathrm{T} 1$.

As aves de cada parcela experimental foram pesadas com um, 21, 35 e 41 dias, para avaliação de ganho de peso médio. Antes da pesagem dos 21 e 41 dias, as aves foram submetidas a jejum prévio de seis horas. A avaliação do consumo de ração foi realizada nos mesmos dias, pesando-se a ração fornecida, o comedouro e as sobras de ração. A conversão alimentar foi obtida através da divisão do consumo médio de ração pelo ganho de peso médio dos frangos. No dia 21, por ocasião da troca de rações da fase inicial para a de crescimento, foi sacrificada uma ave em cada boxe para avaliação visual das características intestinais na região do duodeno, divertículo e pré-cecal, observando-se a integridade da membrana serosa e lesões no lúmen do intestino. Os escores das lesões foram classificados de zero a quatro; sendo 0, sem lesões; 1 , com alguns pontos congestos ou hemorrágicos; 2 , com mais do que cinco pontos congestos numa área de $1 \mathrm{~cm}^{2} ; 3$, com mais do que cinco pontos congestos por área de $1 \mathrm{~cm}^{2}$, em mais do que uma área do intestino e 4, áreas de congestão e/ou hemorragia no intestino. Ao final de cada fase do experimento, foram coletadas três amostras de cama de cada boxe para determinação da umidade da cama.

Ao abate, uma ave em cada boxe foi sangrada, depenada, escaldada e eviscerada. Após resfriamento de 4 horas, as gorduras da região abdominal foram retiradas e pesadas, sendo os resultados expressos em percentagem do peso de carcaça. As variáveis avaliadas foram: NA21, NA35 e NA41= número de aves aos 21, 35 e 41 dias; MS21D e MS41D = matéria seca da cama com 21 e 41 dias; PM1, PM21, PM35 e PM41 = peso médio com 1, 21, 35 e 41 dias; CRM121, CRM2235 e CRM3641 = consumos de ração médios, nos períodos de 1 a 21, 22 a 35 e 36 a 41 dias; CAM121, CAM2235 e CAM3641 = conversões alimentares médias de 1 a 21, 22 a 35 e

Tabela 1 - Composição proximal e energética de alguns dos ingredientes utilizados ${ }^{\mathrm{a}}$.

\begin{tabular}{|c|c|c|c|c|}
\hline Composição & Milho & Farinha de carne e ossos & Farinha de vísceras & Farelo de soja \\
\hline $\mathrm{PB}, \%$ & $8,18^{\mathrm{b}}$ & $52,52^{b}$ & $60,97^{\mathrm{b}}$ & $45,56^{\mathrm{b}}$ \\
\hline EM, kcal/kg & 3.329 & 2.280 & $3.072^{c}$ & 2.440 \\
\hline Cálcio, \% & 0,03 & 9,40 & 4,69 & 0,23 \\
\hline Fósforo total, \% & 0,28 & 4,58 & 2,61 & 0,61 \\
\hline Fósforo disponível, \% & 0,08 & 4,58 & 2,61 & 0,14 \\
\hline Met+Cis, \% & 0,36 & 1,15 & 1,76 & 1,30 \\
\hline Lisina, \% & 0,25 & 2,42 & 3,32 & 2,83 \\
\hline Triptofano, \% & 0,06 & 0,25 & 0,48 & 0,60 \\
\hline Treonina, \% & 0,29 & 1,54 & 2,18 & 1,73 \\
\hline
\end{tabular}

${ }^{\mathrm{a}}$ Dados obtidos da matriz da formulação das rações

bValores analisados no laboratório de nutrição da Embrapa Suínos e Aves

${ }^{\mathrm{c}}$ Valor calculado (BELLAVER et al. 2001 ${ }^{\mathrm{a}}$ ). 
36 a 41 dias; GPM121, GPM135 e GPM141 = ganhos de pesos médios de 1 a 21, 1 a 35 e 1 a 41 dias; CAM121, CAM135 e CAM141 = conversões alimentares médias de 1 a 21, 1 a 35 e 1 a 41 dias. Também foram avaliadas, por escore visual, as lesões nos pés e peito (presença ou ausência de lesões), pesos das partes e órgãos, bem como, calculadas as porcentagens de peito (PPC), de gordura (PGC) e de peito + coxa + sobrecoxa (PCSCP) nas carcaças. A carcaça foi considerada como a soma dos pesos das asas, coxas, sobrecoxas, peito, dorso e gordura abdominal, sem cabeça, pés e órgãos.

No dia da chegada, os pintos foram pesados individualmente e formados grupos do maior para o menor peso, distribuídos por intervalo de peso vivo, não maior do que 3 gramas. As aves então foram alocadas nas unidades experimentais em blocos com base no peso vivo. O experimento contou com quatro tratamentos e cinco repetições por sexo, distribuídos em 40 (4x5x2) unidades experimentais, em que os dados foram analisados através do pacote estatístico SAS (2000), de acordo com o modelo estatístico: $\mathrm{Y}_{\mathrm{ijkl}}=\mathrm{m}+$ $\mathrm{D}_{\mathrm{i}}+\mathrm{S}_{\mathrm{j}}+\mathrm{B}_{\mathrm{k}}+(\mathrm{DS})_{\mathrm{ij}}+\mathrm{e}_{\mathrm{ijkk}}$, onde: $\mathrm{Y}_{\mathrm{ijkl}}=$ observação na parcela l, recebendo a dieta $\mathrm{i}$, no sexo j e bloco $\mathrm{k} ; \mathrm{m}=$ constante associada a todas as observações; $D_{i}=$ efeito da dieta $\mathrm{i}$, sendo que $\mathrm{i}=1 . . .4$; $\mathrm{S}_{\mathrm{j}}=$ efeito do sexo $\mathrm{j}$, sendo que $\mathrm{j}=1,2 ; \mathrm{B}_{\mathrm{k}}=$ efeito do bloco $\mathrm{k}$, sendo $\mathrm{k}=$ 1 ...5; (DS $)_{\mathrm{ij}}=$ efeito da interação da dieta i com o sexo $\mathrm{j}$; $\mathrm{e}_{\mathrm{ijkl}}=$ erro experimental associado a cada observação sendo normalmente distribuído com média 0 e variância $\mathrm{s}^{2}$. O modelo estatístico utilizado foi testado pelo teste de $\mathrm{F}$ e as médias entre os tratamentos, comparadas pelo teste t de Student nas probabilidades indicadas nas tabelas 2 e 3 .

\section{RESULTADOS E DISCUSSÕES}

A performance das aves é mostrada na tabela 2, e as variáveis relacionadas com o abate na tabela 3. De uma maneira geral, o experimento pode ser considerado consistente em seus resultados, visto que o modelo estatístico empregado apresentou bons ajustes e pequenos coeficientes de variação. Entre os resultados alcançados, verifica-se que o número de aves vivas aos 21, 35 e 41 dias foi diferente apenas para o efeito de sexo aos 41 dias, sendo que as fêmeas tiveram maior sobrevivência $(\mathrm{P}<0,05)$.

Houve significativa diminuição da matéria seca da cama tanto aos 21 dias $(\mathrm{P}<0,0001)$ como aos 42 dias $(\mathrm{P}<0,0002)$, motivada pela fonte protéica e teores de proteína das dietas vegetarianas. Esse efeito também é verificado para os sexos, mas age independentemente, sendo que as fêmeas apresentaram maior teor de matéria seca na cama do que os machos em ambas as fases $(\mathrm{P}<0,003)$. Esse resultado pode ser parcialmente explicado pelo aumento de $\mathrm{K}$ das dietas com FS, estando de acordo com ROSTAGNO et al. (2002) que verificaram aumento do consumo de água em dietas com maiores níveis de $\mathrm{PB}$ oriunda do FS.

Aos 21 dias, não foi possível detectar nenhuma diferença entre as dietas; porém, com 35 e 41 dias, observou-se que a dieta 1, com FOA, apresentou menores pesos médios do que na dieta 2 . A dieta 4 foi a que apresentou melhores resultados de peso médio aos 41 dias $(\mathrm{P}<0,0002)$. Para essas variáveis, os machos apresentam maior peso $(\mathrm{P}<0,0001)$. Da mesma forma foram os resultados dos ganhos de peso de 1 a 21, 1 a 35 e 1 a 41 dias. No período total (1 a 41 dias), os ganhos favoreceram a dieta 4, que foi superior; a dieta 1 foi inferior às demais $(\mathrm{P}<0,0002)$. O melhor desempenho em relação aos demais tratamentos foi devido ao maior nível de aminoácidos da dieta 4 (eg 1,23\% de lisina) em comparação aos outros tratamentos, o que eqüivale a cerca de $6 \%$ a mais de lisina digestível. Esperavase similaridade entre os ganhos médios das dietas 1 (2.266g) e 2 (2.307g), mas isso não aconteceu devido à sensibilidade do experimento que detectou como significativa $(\mathrm{P}<0,05)$ a pequena diferença verificada $(1,80 \%)$. Entretanto, uma simulação feita por GIROTTO et al. (2002), com preços de Outubro de 2002, mostrou uma diminuição entre 6 e 14 \% no custo de produção das rações com FOA em relação àquelas com FS. Embora não seja o objetivo desse trabalho analisar os custos, infere-se com base nos resultados e na literatura, que a dieta 1 , com FOA, é a mais econômica na situação de preços pois o FS é mais caro do que as farinhas de origem animal.

Não houve benefício do aumento da PB de 22 para 23 e o benefício da melhora de desempenho com $24 \%$ de PB pode ser atribuído ao aumento do nível de aminoácidos dessa dieta.

Conforme foi demonstrado por BELLAVER et al. (2001b), a inclusão de cerca de 7\% de FV substituindo o FS, em dietas para frangos de corte, melhora o desempenho até os 21 dias e não altera o desempenho até os 42 dias, em dietas formuladas dentro do conceito de proteína ideal. É possível que a diferença no desempenho das dietas 1 e 2, tenha sido devido à maior energia calculada para as FOA na formulação das dietas do que o que realmente as mesmas continham; ou, ao insuficiente aporte de triptofano digestível na dieta com FOA (1), na fase de crescimento, mesmo que esse tenha sido parcialmente corrigido na formulação. 
Tabela 2 - Efeitos das dietas com farinhas de origem animal (FOA) ou farelo de soja (FS) dos sexos sobre o desempenho de frangos (1-41 d).

\begin{tabular}{|c|c|c|c|c|c|c|c|c|c|c|c|c|}
\hline \multirow{2}{*}{ Variáveis ${ }^{3}$} & \multirow{2}{*}{ Obs. } & \multicolumn{4}{|c|}{ Tratamentos } & \multirow{2}{*}{$\mathrm{EPM}^{1}$} & \multirow{2}{*}{ Prob $>F^{1}$} & \multicolumn{2}{|c|}{ Sexos } & \multirow{2}{*}{$\mathrm{EPM}^{2}$} & \multirow{2}{*}{ Prob $>F^{2}$} & \multirow{2}{*}{$\begin{array}{c}\mathrm{CV} \text { do } \\
\text { modelo,\% }\end{array}$} \\
\hline & & $\begin{array}{c}1=\mathrm{FOA} \\
22 \% \mathrm{~PB}\end{array}$ & $\begin{array}{l}2=\mathrm{FS} \\
22 \% \mathrm{~PB}\end{array}$ & $\begin{array}{c}3=2 \\
+1 \% \mathrm{~PB}\end{array}$ & $\begin{array}{c}4=2 \\
+2 \% \mathrm{~PB}\end{array}$ & & & Machos & Fêmeas & & & \\
\hline NA21 & 40 & 29,70 & 29,30 & 29,50 & 29,60 & 0,2287 & 0,6475 & 29,40 & 29,65 & 0,1617 & 0,2837 & 2,45 \\
\hline NA35 & 40 & 28,70 & 28,20 & 28,30 & 28,20 & 0,2416 & 0,4205 & 28,15 & 28,55 & 0,1709 & 0,1090 & 2,70 \\
\hline NA41 & 40 & 28,60 & 28,20 & 28,20 & 28,00 & 0,2793 & 0,4982 & 27,95 & 28,55 & 0,1975 & 0,0405 & 3,13 \\
\hline MS21D & 40 & 77,68 & 72,45 & 73,14 & 70,47 & 0,9441 & 0,0001 & 71,88 & 74,99 & 0,6676 & 0,0027 & 4,07 \\
\hline MS41D & 40 & 66,65 & 64,75 & 61,22 & 58,36 & 1,2170 & 0,0002 & 60,22 & 65,27 & 0,8605 & 0,0003 & 6,13 \\
\hline PM1 & 40 & 43,39 & 43,36 & 43,37 & 43,41 & 0,0468 & 0,8721 & 43,45 & 43,32 & 0,0331 & 0,0081 & 0,34 \\
\hline PM21 & 40 & 824,06 & 835,40 & 826,77 & 842,40 & 6,8879 & 0,2425 & 888,89 & 775,43 & 4,8705 & 0,0001 & 2,62 \\
\hline PM35 & 40 & 1873,24 & 1916,80 & 1914,16 & 1937,11 & 10,2251 & 0,0013 & 2071,98 & 1748,67 & 7,23 & 0,0001 & 1,69 \\
\hline PM41 & 40 & 2309,11 & 2350,64 & 2349,10 & 2403,80 & 12,8849 & 0,0002 & 2579,07 & 2127,26 & 9,1110 & 0,0001 & 1,73 \\
\hline $\mathrm{CRM}_{121^{4}}$ & 40 & 1105,42 & 1102,05 & 1085,26 & 1081,82 & 7,1482 & 0,0624 & 1153,43 & 1033,84 & 5,0545 & 0,0001 & 2,07 \\
\hline CRM2235 & 40 & 1816,68 & 1892,91 & 1885,71 & 1907,01 & 13,1712 & 0,0002 & 2018,04 & 1733,12 & 9,3135 & 0,0001 & 2,22 \\
\hline CRM3641 & 40 & 1160,46 & 1238,09 & 1223,89 & 1220,40 & 21,3569 & 0,0728 & 1286,01 & 1135,41 & 15,1016 & 0,0001 & 5,58 \\
\hline GPM121 & 40 & 780,67 & 792,04 & 783,40 & 798,99 & 6,8921 & 0,2436 & 845,44 & 732,11 & 4,87 & 0,0001 & 2,76 \\
\hline GPM135 & 40 & 1829,85 & 1873,44 & 1870,79 & 1893,70 & 10,2261 & 0,0013 & 2028,53 & 1705,35 & 7,2310 & 0,0001 & 1,73 \\
\hline GPM141 & 40 & 2265,71 & 2307,28 & 2305,73 & 2360,39 & 12,8799 & 0,0002 & 2535,62 & 2083,94 & 9,1075 & 0,0001 & 1,76 \\
\hline CAM121 & 40 & 1,42 & 1,39 & 1,39 & 1,36 & 0,0111 & 0,0059 & 1,36 & 1,41 & 0,0078 & 0,0002 & 2,52 \\
\hline CAM135 & 40 & 1,54 & 1,54 & 1,53 & 1,51 & 0,0070 & 0,0119 & 1,50 & 1,56 & 0,0050 & 0,0001 & 1,45 \\
\hline CAM141 & 40 & 1,71 & 1,73 & 1,72 & 1,68 & 0,0095 & 0,0042 & 1,65 & 1,77 & 0,0067 & 0,0001 & 1,75 \\
\hline
\end{tabular}

${ }^{1}$ Erro padrão da média e probabilidades de diferenças significativas pelo teste $\mathrm{F}$ para tratamentos; ${ }^{2}$ Erro padrão da média e probabilidades de diferenças significativas pelo teste F para sexos; ${ }^{3}$ NA21, NA35 e NA41= número de aves aos 21, 35 ou 41 dias; MS21D e MS41D = matéria seca da cama com 21 ou 41 dias; PM1, PM21, PM35 e PM41 = peso médio com 1, 21, 35 ou 41 dias; CRM121, CRM2235 e CRM3641 = consumos de ração médios nos períodos de 1 a 21, 22 a 35 ou 36 a 41 dias; CAM121, CAM2235 e CAM3641 = conversões alimentares médias de 1 a 21, 22 a 35 ou 36 a 41 dias; GPM121, GPM135 e GPM141 = ganhos de pesos médios de 1 a 21, 1 a 35 ou 1 a 41 dias; CAM121, CAM135 e CAM141 = conversões alimentares médias de 1 a 21, 1 a 35 ou 1 a 41 dias; ${ }^{4}$ Interação significativa $(\mathrm{P}<0,05)$.

Em todos os períodos, a conversão alimentar da dieta 4, com formulação de ingredientes vegetais e acrescida de $2 \%$ de PB foi melhor do que a dieta 2, similar na composição de ingredientes e também da dieta 1, com FOA. Para o mesmo nível de $\mathrm{PB}$, no período de 1 a 42 dias, a dieta com FOA (dieta 1) apresentou melhor conversão alimentar do que a dieta vegetal (dieta 2). O efeito de sexo foi manifestado em vários níveis de significância, com aumentos dos consumos de ração e ganhos de peso, bem como, melhoria das conversões alimentares para os machos em relação às fêmeas.

Na tabela 3, observa-se que não houve diferenças devidas a tratamentos, exceto para o peso dos pés $(\mathrm{P}>0,05)$. $\mathrm{O}$ menor peso dos pés do tratamento com FOA pode estar relacionado com a maior porcentagem de matéria seca da cama desse tratamento em relação àqueles com FS. Os machos apresentaram melhoria geral nas variáveis de carcaça. Não foram observadas diferenças nas lesões intestinais devido ao maior erro na estimativa dessas variáveis; porém, nota-se que a dieta 1 apresentou cerca da metade do valor numérico das demais dietas para as lesões de duodeno. Não foram detectadas lesões nos pés e peito que pudessem ser atribuídas aos efeitos dos tratamentos. Os machos apresentaram gordura abdominal e porcentagens de peito semelhantes a das fêmeas $(\mathrm{P}>0,05)$, mas a porcentagem de gordura abdominal foi menor nos machos do que nas fêmeas $(\mathrm{P}<0,0005)$. 
Tabela 3 - Efeitos das dietas com farinhas de origem animal (FOA) ou farelo de soja (FS) e dos sexos sobre as lesões, pesos e porcentagens obtidas com frangos de corte abatidos aos 41 dias de idade.

\begin{tabular}{|c|c|c|c|c|c|c|c|c|c|c|c|c|}
\hline \multirow{3}{*}{ Variáveis } & \multirow{3}{*}{ Obs. } & \multicolumn{4}{|c|}{ Tratamentos } & \multirow{3}{*}{$\mathrm{EPM}^{1}$} & \multirow{3}{*}{ Prob $>F^{1}$} & \multicolumn{2}{|c|}{ Sexos } & \multirow{3}{*}{$\mathrm{EPM}^{2}$} & \multirow{3}{*}{ Prob $>\mathrm{F}^{2}$} & \multirow{3}{*}{$\begin{array}{c}\text { CV do modelo, } \\
\%\end{array}$} \\
\hline & & $1=\mathrm{FOA}$ & $2=\mathrm{FS}$ & $3=2$ & $4=2$ & & & \multirow{2}{*}{ Machos } & \multirow{2}{*}{ Fêmeas } & & & \\
\hline & & & $22 \% \mathrm{~PB}$ & $+1 \% \mathrm{~PB}$ & $+2 \% \mathrm{~PB}$ & & & & & & & \\
\hline $\begin{array}{l}\text { Lesões no } \\
\text { duodeno }{ }^{3}\end{array}$ & 40 & 0,30 & 0,60 & 0,50 & 0,70 & 0,19 & 0,49 & 0,60 & 0,45 & 0,13 & 0,4294 & 112,69 \\
\hline $\begin{array}{l}\text { Lesões no } \\
\text { divertículo }\end{array}$ & 40 & 0,10 & 0,20 & 0,10 & 0,10 & 0,11 & 0,88 & 0,10 & 0,15 & 0,08 & 0,6462 & 272,55 \\
\hline Peso abate, g & 40 & 2306,90 & 2347,70 & 2312,20 & 2349,90 & 18,31 & 0,22 & 2541,05 & 2117,30 & 12,95 & 0,0001 & 2,49 \\
\hline Carcaça, g & 40 & 1770,10 & 1785,20 & 1751,30 & 1778,70 & 14,99 & 0,42 & 1935,05 & 1607,60 & 10,60 & 0,0001 & 2,68 \\
\hline Asas, g & 40 & 179,30 & 187,80 & 182,80 & 183,60 & 2,61 & 0,17 & 200,75 & 166,00 & 1,84 & 0,0001 & 4,49 \\
\hline Coxas, g & 40 & 228,60 & 235,60 & 231,20 & 231,60 & 3,56 & 0,58 & 262,10 & 201,40 & 2,51 & 0,0001 & 4,85 \\
\hline Sobre coxas, g & 40 & 355,10 & 352,40 & 339,30 & 350,00 & 5,36 & 0,20 & 382,65 & 315,75 & 3,79 & 0,0001 & 4,85 \\
\hline Peito, g & 40 & 524,20 & 518,00 & 519,10 & 522,40 & 8,78 & 0,96 & 564,45 & 477,40 & 6,21 & 0,0001 & 5,33 \\
\hline Dorso, g & 40 & 439,20 & 451,90 & 438,60 & 452,80 & 6,39 & 0,24 & 485,90 & 405,35 & 4,52 & 0,0001 & 4,53 \\
\hline Gord. Abd., g & 40 & 43,60 & 41,30 & 41,50 & 39,50 & 2,59 & 0,74 & 40,05 & 42,90 & 1,83 & 0,2806 & 19,75 \\
\hline Cabeça, g & 40 & 62,00 & 62,10 & 62,60 & 61,10 & 1,93 & 0,96 & 67,95 & 55,95 & 1,37 & 0,0001 & 9,87 \\
\hline Pés, g & 40 & 84,20 & 93,00 & 86,80 & 90,20 & 1,83 & 0,01 & 104,60 & 72,50 & 1,29 & 0,0001 & 6,52 \\
\hline Fígado, g & 40 & 43,70 & 42,40 & 43,70 & 42,60 & 1,28 & 0,83 & 45,10 & 41,10 & 0,90 & 0,0041 & 9,39 \\
\hline Coração, g & 40 & 11,90 & 12,40 & 10,80 & 12,20 & 0,60 & 0,26 & 13,35 & 10,30 & 0,42 & 0,0001 & 16,07 \\
\hline Moela, g & 40 & 33,60 & 36,00 & 35,90 & 38,40 & 1,39 & 0,14 & 37,40 & 34,55 & 0,99 & 0,0504 & 12,25 \\
\hline $\mathrm{PPC}^{4}, \%$ & 40 & 29,66 & 28,97 & 29,67 & 29,43 & 0,43 & 0,63 & 29,17 & 29,69 & 0,30 & 0,2446 & 4,63 \\
\hline $\mathrm{PGC}^{4}, \%$ & 40 & 2,48 & 2,35 & 2,38 & 2,26 & 0,15 & 0,79 & 2,07 & 2,67 & 0,11 & 0,0005 & 20,39 \\
\hline $\mathrm{PCSCP}^{4}, \%$ & 40 & 62,58 & 61,86 & 62,21 & 62,05 & 0,38 & 0,59 & 62,49 & 61,86 & 0,27 & 0,1082 & 1,94 \\
\hline
\end{tabular}

${ }^{1}$ Erro padrão da média e probabilidades de diferenças significativas pelo teste $\mathrm{F}$ para tratamentos; ${ }^{2}$ Erro padrão da média e probabilidades de diferenças significativas pelo teste $\mathrm{F}$ para sexos; ${ }^{3}$ Escores de lesão na mucosa das regiões do duodeno e divertículo, não havendo nenhum sinal de lesão na região pré-cecal; ${ }^{4} \mathrm{PPC}=$ porcentagem de peito na carcaça, $\mathrm{PGC}=$ porcentagem de gordura abdominal na carcaça, $\mathrm{PCSCP}=$ porcentagem de peito+coxa+s.coxa na carcaça.

\section{CONCLUSÕES}

Houve diminuição da matéria seca da cama das aves devido à presença de ingredientes exclusivamente vegetais e aumento do teor de proteína das dietas, sendo que as fêmeas apresentam maior teor de matéria seca das camas do que os machos. A menor porcentagem de matéria seca da cama de aviário das dietas vegetais pode ter ocasionado o aumento do peso dos pés.

Com o aumento do nível de aminoácidos digestíveis das dietas houve melhoria no desempenho das aves alimentadas com proteína vegetal, não havendo diferença nos cortes da carcaça devido às fontes protéicas.

\section{AGRADECIMENTOS}

Os autores agradecem a participação financeira no contrato número 99000/001-02 celebrado entre a Ajinomoto Biolatina, FUNDAGRO e da Embrapa Suínos e Aves, bem como ao CNPq na concessão de bolsas.

\section{REFERÊNCIAS BIBLIOGRÁFICAS}

ABEF. Relatório anual 2001. Acesso em: 28 nov. 2002. On line. Disponível em: <http://www.abef.com.br>

BAKER, D.H.; HAN, Y. Ideal amino acid profile for chicks during the first three weeks posthatching. Poultry Science. v.73, p.1441-1447, 1994.

BELLAVER, C. et. al. Estimativas da energia metabolizável e dos coeficientes de digestibilidade dos aminoácidos de 20 farinhas de vísceras de aves. In: CONFERÊNCIA APINCO 2001 DE CIÊNCIA E TECNOlogia AVÍCOLA, 2001, Campinas, SP. Anais... Campinas : FACTA, 2001a. (Trabalhos de Pesquisa). p.46.

BELLAVER, C. et al. Substituição parcial do farelo de soja pela sarinha de vísceras de aves em dietas balanceadas com base na proteína e em aminoácidos totais ou digestíveis para frangos de corte. Revista Brasileira de Ciência Avícola, v.3, n.3, p.233-240, 2001b.

BRUGALLI, I. et al. Efeito do tamanho da partícula e do nível de substituição nos valores energéticos da farinha de carne e ossos para pintos de corte. Revista Brasileira Zootecnia, v.28, n.4, p.753-757, 1999. 
GIROTTO, A.F. et al. Como amenizar a crise da suinocultura. Revista Porkworld, v.2, n.9, p.20-23, 2002 .

MOURA, C.C. et al. Farinha de penas e sangue em rações para suínos em crescimento. Revista Brasileira de Zootecnia v.23, n.4, p.632-641, 1994.

NRC. Nutrient requeriments of poultry. Washington, DC : National Academy of Science, 1994. 155p.

PARSONS, C.M.; BAKER, D.H. The concept and use of ideal proteins in the feeding of nonruminants. In REUNIÃO ANUAL DA SOCIEDADE BRASILEIRA DE ZOOTECNIA, 31., 1994, Maringá. Anais... Maringá : SBZ, 1994. p.114-128.
PARSONS, C.M.; WANG, X. Dietary formulation with meat and bone meal on a total versus a digestible or bioavailable amino acid basis. Poultry Science, v.77, p.1010-1015, 1998.

PEREIRA, L.E.J. et al. Farinha de vísceras de aves em substituição ao farelo de soja na alimentação de suínos em crescimento e terminação. Revista Brasileira de Zootecnia, v.23, n.6, p.930-939, 1994.

ROSTAGNO, H.S. et al. Dietas vegetais para frangos de corte. In: SIMPÓSIO BRASIL SUL DE AVICULTURA, 3. 2002, Chapecó. Anais... Concórdia : Embrapa Suínos e Aves, 2002. p.41-47.

SAS INSTITUTE INC. SAS user's guide: statistics. Cary: SAS Institute, 2000. 1 CD-ROM. 